\title{
COMPARATIVE STUDY OF POLYPHENOL, FLAVONOID, AND ANTIOXIDANT ACTIVITY OF VARIOUS MEDICINAL PLANTS COLLECTED FROM DIFFERENT ALTITUDES
}

\author{
BIGYAN JOSHI ${ }^{1 *}$, NETRA LAL BHANDARI ${ }^{2}$, SUNITA SHRESTHA $^{2}$, RAJENDRA GYAWALI $^{1}$, PANNA THAPA ${ }^{1 *}$
}

${ }^{1}$ Department of Pharmacy, School of Science, Kathmandu University, Dhulikhel, Kavre, Nepal. ${ }^{2}$ Department of Chemistry, Tri-Chandra Multiple Campus, Tribhuvan University, Kathmandu, Nepal. Email: pannathapa@ku.edu.np/joshibigyan26@gmail.com

Received: 22 March 2021, Revised and Accepted: 14 July 2021

\section{ABSTRACT}

Objectives: The main aim of this investigation is to explore the folklore medicinal flora located at Terai and the lesser Himalayan region of Nepal and has a comparative study on phenol, flavonoid, and antioxidant activity that would bring forth a factual basis for its use in the traditional therapy of various health ailments.

Methods: Folin-Ciocalteu and Colorimetric aluminum chloride methods were used for the estimation of total polyphenolic and flavonoid content, respectively. Moreover, antioxidant activity was determined by DPPH radical scavenging activity.

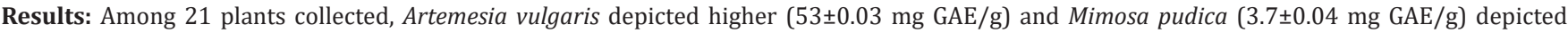
lower phenolic content whereas the highest flavonoid content is observed in Syzygium cumini and the lowest value in Mentha piperita. Almost all the collected specimen demonstrated antioxidant activity, among which Eupatorium adenophorum and Rhododendron anthopogon demonstrated lower and higher antioxidant activity, respectively. Moreover, phenol and flavonoid content showed a weak correlation with the antioxidant activity indicating the major antioxidant to be different compounds other than phenols or flavonoids.

Conclusion: The present study confirms the antioxidant activity of the collected plant specimen and defends its ethnobiological use as a possible natural antioxidant. Furthermore, the result of antioxidant properties encourages their application in medicinal health, functional food, and biopharmaceutics.

Keywords: Phenol, Flavonoid, Antioxidant.

(C) 2021 The Authors. Published by Innovare Academic Sciences Pvt Ltd. This is an open access article under the CC BY license (http://creativecommons.org/ licenses/by/4.0/) DOI: http://dx.doi.org/10.22159/ajpcr.2021v14i9.42564. Journal homepage: https://innovareacademics.in/journals/index.php/ajpcr

\section{INTRODUCTION}

Numerous aromatics, spices, and medicinal plants are being abundantly used by the modern analyst to develop natural antioxidant formulations for food, cosmetic, pharmaceutical, and therapeutic applications [1]. An antioxidant neutralizes the free radicals or inhibits the oxidation of other substances. During various physiological and biochemical processes, environmental pollutions, UV and gamma radiation, as well as physical stress, free radicals, and other reactive oxygen species are generated in the human body [2,3]. Reactive oxygen species (ROS) and nitrogen (RNS) species act as pro-oxidants that either induces oxidative stress or inhibit the antioxidant activity and cause damage to proteins, lipid peroxidation, and fragmentation of deoxyribonucleic acid strand [3]. The process ultimately leads to cellular injury, aging, cancer, and hepatic, neurodegenerative, cardiovascular, and renal disorders $[4,5]$.

The human body consists of superoxide dismutase, glutathione peroxidase, and non-enzymatic antioxidants such as Vitamins E and C, thiol antioxidants, carotenoids, and other compounds as an endogenous antioxidant enzyme that can reduce oxidative stress [6] and therefore, help in maintaining the ideal cellular activity $[7,8]$. Although under the ameliorative behavior of free radicals, these defensive endogenous antioxidants are insufficient, thus, directing the supply of dietary antioxidants $[8,9]$. Phenolic acids, polyphenols, and flavonoids are the common natural antioxidant products found in plants and supplements that protect plants, fruits, vegetables as well as human beings from oxidative damage [1].A cautious selection of the physicochemical characteristics of polyphenols is crucial as the bioavailability and chemical reactivity of phenols and flavonoids strongly affect its activity against ROS [4].
In recent decades, the physiological finding of ideal natural antioxidants from edible materials such as spices and herbs that can readily be absorbed, quench free radicals and cause metal inactivation are increasing $[6,10]$. There is a considerable quest for natural antioxidant molecules such as phenol, flavonoids obtained from plants as presently accessible artificial antioxidants, such as butylated hydroxyl anisole (BHA), butylated hydroxyl toluene (BHT), tertiary butylated hydroquinone, and gallic acid esters are reported to have genotoxic and carcinogenic effects $[6,11]$. Therefore, the investigations are mostly focused on congenital plant phytochemicals that are natural, non-synthetic and can not only counteract free-radicalinduced oxidative stress and protect the human body from oxidative cell damage, diabetes, inflammation, and asthma but also be active in cardioprotective antitumor and antibacterial activities to a greater or lesser extent $[2,11,12]$ as well as can overcome the side effects of synthetic antioxidants.

In developing countries, most of the populations rely on folklore medicine and are benefited from Ayurveda, a traditional medicinal herbal treatment for healthcare [13]. Nepal is a lavish country having an abundance of flora and fauna because of the altitudinal variation, climatic differences, varied topography, and abundant ecological habitats [14]. However, there is still limited scientific exploration and a lack of scientific proof on justifying the ethnomedicinal uses of Nepalese medicinal plants present in different altitudes. Therefore, the present investigation focuses on the collection of medicinal plants from Terai and the lesser Himalayan region of Nepal and studies its potential antioxidant behavior via DPPH radical scavenging activity. Furthermore, the study attempts to establish the correlation between phenolic and flavonoid content with the DPPH radical scavenging activity of 22 plant extracts that might be an encouraging source of natural antioxidants. 


\section{METHODS}

\section{Plant material collection and sample preparation}

Twenty-two different traditional medicinal plants from Terai and lesser Himalayas of Nepal including areas such as Nepalthok Khurkot, Dhulikhel, Sindhuli, Hetauda, Parsa, Pathlaiya, Niijgadh, and Bardibash were collected and evaluated in this study. Plant material was gathered near October and authenticated according to their scientific name by the national herbarium and Plant Laboratories, Godawari, Lalitpur. Plant material was washed, dried, and powdered by a mechanical grinder at room temperature. The powdered herbal samples $(20 \mathrm{~g}$ each) were suspended and extracted in $250 \mathrm{~mL}$ of $80 \%$ methanol (v/v) through decoction process as shown in Fig. 1 for three times and evaporated until the dark-colored solvent is obtained to extract oils, volatile organic compounds, and other various chemical substances present in the plant materials. The herbal samples were mashed for maximum dissolution of the sample to the solvent used. The extract was then filtered and dried using a vacuum rotary evaporator. Thus, concentrated samples were subsequently weighed and kept at $4^{\circ} \mathrm{C}$ until use.A list of the names of the medicinal plants collected with their family name and parts of the plant used for the extraction process is expressed in Tables 1 and 2.

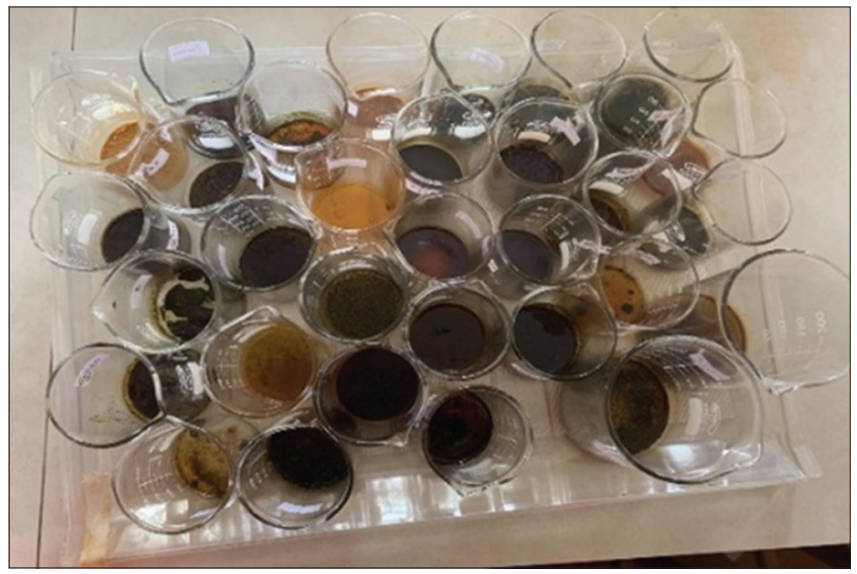

Fig. 1: Extraction of crude plant specimen via decoction process
Determination of total polyphenolic compounds

The total phenolic content (TPC) of the extracted sample was determined using the Folin-Ciocalteau assay following the methods mentioned in Settharaksa et al. 2012 where gallic acid was used as a standard antioxidant [15]. The extracted samples $(12.5 \mu \mathrm{L})$ were mixed with $50 \mu \mathrm{L}$ of water and $12.5 \mu \mathrm{L}$ of Folin-Ciocalteau reagent for 6 min and then $125 \mu \mathrm{L}$ of $7 \%$ sodium carbonate $\left(\mathrm{Na}_{2} \mathrm{CO}_{3}\right)$ along with $100 \mu \mathrm{L}$ of water was added. After the incubation at room temperature for $90 \mathrm{~min}$, the absorbance was measured at $760 \mathrm{~nm}$ and all the determinations were performed in triplicates. Total phenolic content was reported as $\mathrm{mg} / \mathrm{g}$ of GAE in reference to a standard curve $(\mathrm{y}=0.0101 \mathrm{x}+0.0622$ and $\left.\mathrm{R}^{2}=0.9891\right)$.

\section{Determination of total flavonoid content}

Total flavonoid content (TFC) was determined by the Colorimetric aluminum chloride method as described in Mundhe et al., 2011 [16]. Aliquots of each plant extracts were separately mixed with $1.5 \mathrm{~mL}$ of methanol, $0.1 \mathrm{~mL} \mathrm{AlCl}{ }_{3} 10 \%$ ), $0.1 \mathrm{~mL}$ of $1 \mathrm{M}$ potassium acetate, and $2.8 \mathrm{~mL}$ of distilled water. The solutions were kept at room temperature for $30 \mathrm{~min}$ and the absorbance of the reaction mixture was measured at $415 \mathrm{~nm}$.A standard calibration curve was prepared by using known concentrations of quercetin at $415 \mathrm{~nm}$. The total flavonoid in the test samples was calculated from the standard calibration curve with quercetin $(0-100 \mu \mathrm{g} / \mathrm{mL})$ which was again used for quantification in triplicates. The regression equation and $\mathrm{R}^{2}$ for calibration curve arey $=$ $0.004 x+0.0376$ and $R^{2}=0.9887$.

The result is expressed in $\mathrm{mg}$ quercetin equivalent/g of sample (mg Qu/g).

\section{DPPH radical scavenging activity}

2,2-Diphenyl-1-picrylhydrazyl (DPPH) radical scavenging activity was determined using the method described in Brand Williams et al. 1995 with some modifications and by the use of synthetic radical DPPH assay [17]. One milliliter of the methanol extracts of the plants $(400,200,100,50$, and $25 \mathrm{mg} / \mathrm{mL})$ was added to $2 \mathrm{~mL}$ of a solution of DPPH radicals. The mixture was shaken continuously and allowed to stand for $30 \mathrm{~min}$ at room temperature. The absorbance (Abs sample) of the resulting solution was measured at $517 \mathrm{~nm}$ using a UV-Vis spectrophotometer and converted into a percentage of antioxidant

Table 1: Total phenolic content expressed as $\mathrm{mg} \mathrm{GAE} / \mathrm{g}$ sample and total flavonoid content as $\mathrm{mg} \mathrm{QE} / \mathrm{g}$ sample

\begin{tabular}{|c|c|c|c|c|c|}
\hline S. No. & Plants & Sample & Parts used & $\begin{array}{l}\text { Total phenolic content } \\
\text { (mg GAE/g sample) }\end{array}$ & $\begin{array}{l}\text { Total flavonoid content } \\
\text { (mg QE/g sample) }\end{array}$ \\
\hline 1. & Artemesia vulgaris & $\mathrm{A}$ & Leaves & $53 \pm 0.03$ & $44.43 \pm 0.01$ \\
\hline 2. & Lemon peel & $\mathrm{B}$ & Fruit peel & $52 \pm 0.03$ & $10.18 \pm 0.02$ \\
\hline 3. & Terminalia chebula & $\mathrm{C}$ & Roots & $46.05 \pm 0.04$ & $28.5 \pm 0.01$ \\
\hline 4. & Eclipta alba (Bhringraj) & $\mathrm{D}$ & Whole plant & $44.3 \pm 0.03$ & $42.43 \pm 0.03$ \\
\hline 5. & Ocimum sanctum & $\mathrm{E}$ & Leaves & $44 \pm 0.01$ & $27.43 \pm 0.03$ \\
\hline 6. & Malus domestica & $\mathrm{F}$ & Fruit peel & $34.25 \pm 0.02$ & $33.81 \pm 0.04$ \\
\hline 8. & Amaranthus leucocarpus (Latte) & $\mathrm{H}$ & Roots & $30.55 \pm 0.04$ & $22.87 \pm 0.03$ \\
\hline 9. & Moringa oleifera leaf & I & Leaves & $29.4 \pm 0.02$ & $14.75 \pm 0.04$ \\
\hline 10. & Rhododendron anthopogon & $\mathrm{J}$ & Leaves & $29.35 \pm 0.02$ & $42.3 \pm 0.01$ \\
\hline 11. & Persea americana (Avocado) & $\mathrm{K}$ & Leaves & $29.05 \pm 0.04$ & $44.62 \pm 0.02$ \\
\hline 12. & Citrus aurantium (Orange peel) & $\mathrm{L}$ & Fruit Peel & $28.5 \pm 0.01$ & $30.12 \pm 0.02$ \\
\hline 13. & Brassica juncea (Sarso) & M & Leaves & $19.6 \pm 0.03$ & $20.68 \pm 0.04$ \\
\hline 14. & Moringa olifera & $\mathrm{N}$ & Whole plant & $18.6 \pm 0.01$ & $12.75 \pm 0.04$ \\
\hline 15. & Achyranthes aspera (Dattiwan) & 0 & Roots & $17.9 \pm 0.01$ & $14.75 \pm 0.03$ \\
\hline 17. & Eupatorium adenophorum & Q & Leaves & $15.55 \pm 0.01$ & $35.06 \pm 0.01$ \\
\hline 18. & Euphoria wallichi & $\mathrm{R}$ & Whole plant & $13.4 \pm 0.04$ & $26.62 \pm 0.04$ \\
\hline 19. & Syzygium cumini (Jamun) & $\mathrm{S}$ & Leaves & $12.8 \pm 0.03$ & $51.5 \pm 0.01$ \\
\hline 20. & Asparagus racemosus (Kurilo) & $\mathrm{T}$ & Stem & $11.15 \pm 0.04$ & $43.5 \pm 0.03$ \\
\hline 21. & Mentha piperita (Mint) & $\mathrm{U}$ & Leaves & $5.1 \pm 0.03$ & $1.93 \pm 0.02$ \\
\hline 22. & Mimosa pudica (Touch me not) & $\mathrm{V}$ & Whole plant & $3.7 \pm 0.04$ & $4.37 \pm 0.01$ \\
\hline
\end{tabular}

Each value is expressed as a mean $\pm \mathrm{SD}(\mathrm{n}=3)$ 
Table 2: Comparison of IC50 values of plant samples with ascorbic acid

\begin{tabular}{|c|c|c|c|c|}
\hline S. No. & Plants & Family & Ascorbic acid (IC50) & $\mathrm{IC}_{50}$ \\
\hline 1. & Artemesia vulgaris & Asteraceae & 45.88 & 92.81481 \\
\hline 2. & Lemon peel & Rutaceae & & 179.6622 \\
\hline 3. & Terminalia chebula & Combretaceae & & 85.4 \\
\hline 4. & Eclipta alba & Asteraceae & & 130.0971 \\
\hline 5. & Ocimum sanctum & Lamiaceae & & 249.64 \\
\hline 6. & Malus domestica & Rosaceae & & 19.63636 \\
\hline 7. & Aegle marmelos & Rutaceae & & 128.0769 \\
\hline 9. & Moringa olifera leaf & Moringaceae & & 36.5 \\
\hline 10. & Rhododendron anthopogan & Ericaceae & & 17.72727 \\
\hline 11. & Persia americana & Lauraceae & & 18.4231 \\
\hline 12. & Citrus aurantium & Rutaceae & & 93.9474 \\
\hline 13. & Brassica juncea & Brasicaceae & & 57.91411 \\
\hline 14. & Moringa olifera & Moringaceae & & 78.78571 \\
\hline 15. & Achyranthes aspera & Amaranthaceae & & 303.5484 \\
\hline 16. & Colocasia esculenta & Araceae & & 273.1818 \\
\hline 19. & Syzygium cumini & Myrtaceae & & 21.10092 \\
\hline 20. & Asparagus racemosus & Asparagaceae & & 129.5 \\
\hline 21. & Mentha piperita & Lamiaceae & & 58.12903 \\
\hline 22. & Mimosa pudica & Fabaceae & & 92.81481 \\
\hline
\end{tabular}

activity (AA) or percentage radical scavenging activity. The \% radical scavenging capacity was calculated using the formula:

$$
\text { Radical scavenging }(\%)=\left[\left(\mathrm{A}_{\mathrm{o}}-\mathrm{A}_{\mathrm{s}}\right) / \mathrm{A}_{\mathrm{o}}\right] \times 100
$$

Where $A_{o}=$ Absorbance of the control (DPPH solution + ethanol) $\mathrm{A}_{\mathrm{s}}=$ Absorbance of the test sample.

The radical scavenger activity was demonstrated in terms of the number of antioxidants required to alleviate the initial DPPH absorbance by $50 \%$. The $\mathrm{IC}_{50}$ value for each sample was determined graphically by plotting the DPPH radical scavenging activity as a function of the sample concentration where ascorbic acid was used as standards. All determinations were achieved in triplicates and the plant extracts used for DPPH radical scavenging activity are shown in Fig. 2.

\section{Statistical analysis}

The data are presented as mean value \pm standard deviation in triplicates for each of the above experiments. An standard calibration curves were prepared for the quantitative estimation of phenol, flavonoids, and antioxidants in the extracts, and all the statistical analysis was carried out through the Microsoft Excel program and Origin 2019b 64bit.

\section{RESULTS AND DISCUSSION}

\section{Determination of total polyphenolic and flavonoid content}

In the present study, the bioactive phytochemicals that have effective immunological, pharmacological, and antioxidant activities, namely, total phenolic and flavonoid content were determined. TPC and TFC were estimated by extrapolation from the calibration curve (Figs. 3 and 4) prepared from gallic acid and quercetin as standard concentrations, respectively, are shown in Table 1. Mimosa pudica (touch me not) depicted the lowest phenolic, 3.7 $\pm 0.04 \mathrm{mg} \mathrm{GAE} / \mathrm{g}$ content whereas Artemisia vulgaris, belonging to a family Asteraceae commonly called mugwort and locally called as Titepati in Nepal manifested higher phenolic ( $53 \pm 0.03 \mathrm{mg} \mathrm{GAE} / \mathrm{g}$ ) and relatively higher flavonoid (44.43 $\pm 0.01 \mathrm{mg} \mathrm{QE} / \mathrm{g}$ ) content than another specimen considered except Persia americana (44.62 $\pm 0.02 \mathrm{mg} \mathrm{QE} / \mathrm{g})$ and Syzygium cumini (51.5 $\pm 0.01 \mathrm{mg} \mathrm{QE} / \mathrm{g}$ ). Even so, Pandey et al., 2017 represented higher TPC $(86.62 \pm 0.04 \mathrm{mg} \mathrm{GAE} / \mathrm{g})$ and TFC $(81.31 \pm$ $0.53 \mathrm{mg} \mathrm{Qu} / \mathrm{g}$ ) relatively to this investigation [18]. The differences in the result might be related to the different extraction process adapted and also due to different environmental conditions of the selected plant. Although disparities in the result are found in other



Fig. 2: Plant extracts for DPPH radical scavenging activity

several kinds of literature, this plant is already proved to have greater health benefits and is commonly used in the treatment of menstrual problems, irregular periods, menopause, and premenstrual syndrome and acts as a sedative and anthelminthic agent [19]. The presence of well-known phenolic compounds, such as caffeic acid, neochlorogenic acid, and ferulic acid in $A$. vulgaris might be responsible for the high level of phenolics [20]. The study performed by Baral et al., 2013, showed a total phenolic concentration of $10.9 \mathrm{GAE} / 100 \mathrm{~g}$ dried plant material of $R$. anthopogon methanolic extract [21]. In comparison to the result of Baral, TPC of the methanolic extract of $R$. anthopogon is better in our study $(29.35 \pm 0.02 \mathrm{mg} \mathrm{GAE} / \mathrm{g})$. Traditionally, leaves and flowers of $R$. anthopogan are not only used as an antioxidant but also are being used to treat sore throats and counteract water-earth illness, remove headaches and back pain, cure cold, blood disorders, bone disease, potato allergies, vomiting, stimulate appetite, and relieve liver disorders in the higher Himalayan region of Nepal where its abundancy is quite high [21].

In this analysis, the content of flavonoids varied from $1.93 \pm 0.02$ to $51.5 \pm 0.01 \mathrm{mg}$ QE/g extract where Syzygium cumini demonstrated higher while Mentha piperita demonstrated the lower flavonoid content than other plant species considered from the Terai region. Analogous TFC of Mentha piperita is also demonstrated in Attanosova et al., 




Fig. 3: Calibration curve of standard gallic acids

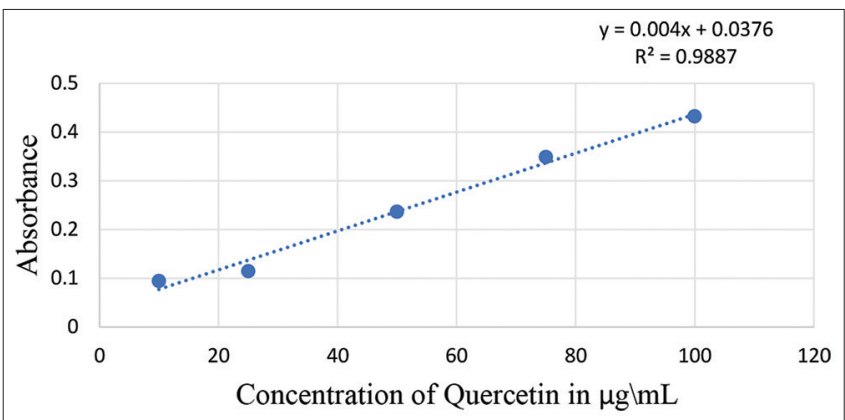

Fig. 4: Calibration curve of standard quercetin

2011 [11]. The presence of the flavonoids and phenolics such as ferulin and catechin is the main reason behind the antioxidant activity of Syzygium cumini [22]. The vast disparities in result between flavonoid and phenolic compound are found in lemon peel, Syzygium cumini, Asparagus racemosus, Moringa olifera leaf, and Terminalia chebula. Eclipta alba (Bringraj), Malus domestica (Apple Peel), Citrus Aurantium (Orange peel), and Brassica juncea (Sarso) manifested comparable antioxidant polyphenols, namely, phenols and flavonoid content.Eclipta alba (Bringraj),an herbaceous false daisy and a commercially attractive plant with excellent hepatotoxic and antidiabetic activities [23] showed TPC of $44.3 \pm 0.03 \mathrm{mg} \mathrm{GAE} / \mathrm{g}$ and TFC of $42.43 \pm 0.03 \mathrm{mg} \mathrm{Qu} / \mathrm{g}$ in this test indicating that these phytochemicals are likely to be responsible for the free-radical scavenging activity. Comparatively, higher values of TPC (52.5 $\pm 0.64 \mathrm{mg} \mathrm{GAE} / \mathrm{g})$, as well as TFC values $(144.62 \pm 1.62 \mathrm{mg} \mathrm{Qu} / \mathrm{g})$ in Eclipta species, are shown in Khurshid et al. 2020 [24].

It is reported that polyphenols and flavonoids are used for the prevention and cure of many diseases associated with free radicals and possess a broad spectrum of chemical and biological activity $[11,20]$. Flavonoids and phenols are considered as an important secondary metabolite containing at least one hydroxyl group that acts as freeradical scavengers and inhibitors of the hydrolytic and oxidative enzyme are known to have a profound anti-inflammatory action and health beneficial effects $[8,11,25]$. The presence of these metabolites in all the plant species though in different amounts is a significant finding of the present study.The phenolic compounds are also known to contribute toward quality and nutritional value through modifying color, taste, aroma, and flavor [26] whereas flavonoids are reported to be accountable for the chelating activity which helps in the reduction of oxidative stress [20].

The absorbance of gallic and quercetin at different concentrations is tabulated in Table 3 whereas the comparative bar diagram for total phenolic and flavonoid content is shown in Fig. 5. Each plant used is labeled from sample $\mathrm{A}$ to $\mathrm{V}$ for simplicity in making a bar graph.

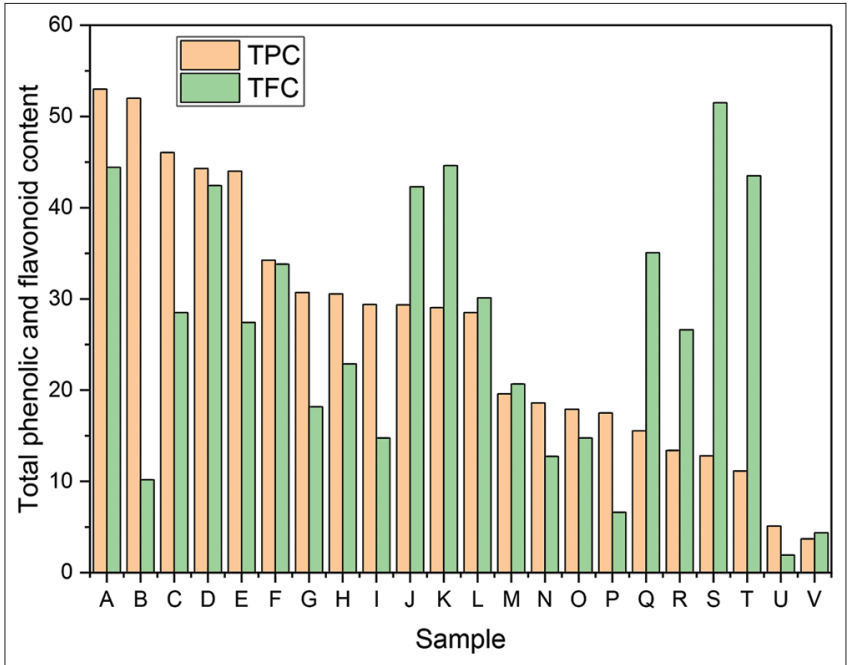

Fig. 5: Bar diagram representing total phenolic and total flavonoid content of the plant specimen

Table 3: Absorbance of standard gallic acid and standard quercetin at different concentration

\begin{tabular}{llll}
\hline $\begin{array}{l}\text { Conc. of gallic } \\
\text { acid } \boldsymbol{\mu g} / \mathbf{m L}\end{array}$ & Absorbance & $\begin{array}{l}\text { Conc. of } \\
\text { quercetin } \boldsymbol{\mu g} / \mathbf{m L}\end{array}$ & Absorbance \\
\hline 10 & 0.185 & 10 & 0.094 \\
20 & 0.285 & 25 & 0.114 \\
40 & 0.421 & 50 & 0.236 \\
60 & 0.674 & 75 & 0.348 \\
80 & 0.831 & 100 & 0.432 \\
100 & 1.121 & & \\
\hline
\end{tabular}

\section{DPPH radical scavenging activity}

Antioxidant therapy is gainingimportance as it is used in the treatment of several metabolic diseasesand the development ofmass scientific programs havestarted with the objective of investigating medicinal propertiesof plants for their potential antioxidant properties [27]. The total antioxidant capacity of the extracts was determined with a synthetic DPPH assay by taking ascorbic acid as a standard solution where the scavenging activity is based on the capacity of an antioxidant to donate hydrogen or an electron to DPPH radical. DPPH itself is deep purple color and gets decolorized or converted to yellow by the respective reduction of DPPH radical to hydrazine, DPPH-H form [28]. Hence, more discoloration of DPPH solution denotes the stronger antioxidant potential of plant extract [29]. The pairing of an electron of radical results in the decrease of absorbance at $517 \mathrm{~nm}$ that are related to the potentiality of the antioxidants. Based on the standard graph plotted between concentration and free-radical scavenging activity and regression equation, the $\mathrm{IC}_{50}$ value of each extract was calculated which is represented in Table 2 which were then compared with standard ascorbic acid.

According to Jadid et al., 2017, $\mathrm{IC}_{50}$ values ranging between 50 and $100 \mathrm{mg} / \mathrm{mL}$ are considered to exhibit intermediate antioxidant activity while extracts with $\mathrm{IC}_{50}$ value ranging between 10 and $50 \mathrm{mg} / \mathrm{mL}$ are considered to possess strong antioxidant activity and $\mathrm{IC}_{50}$ value $>100 \mu \mathrm{g} / \mathrm{mL}$ showed weak antioxidant activity [30]. In this response, Eupatorium adenophorum with a highIC ${ }_{50}$ value412.439 represent low antioxidant activity, followed by Achyranthes aspera (Dattiwan), 303.5484, Amaranthus leucocarpus (Latte), 288, whereas Rhododendron anthopogan exhibited low $\mathrm{IC}_{50}$ value 17.72 before Persia americana, 18.42 Malus domestica, 19.63, Syzygium cumini, 21.10092, 
Moringa olifera with $36.5 \mathrm{IC}_{50}$ value, demonstrating about the highest antioxidant activity. Eshwarappa et al., 2014, exhibited the strong radical scavenging activity of the methanol extracts of Syzygium cumini similar to this study with $\mathrm{IC}_{50}$ value ranging between 10 and $50 \mathrm{mg} / \mathrm{mL}$ [27]. While Navarro et al., 2018, reported less IC ${ }_{50}$ value (4.54) of the peel extracts of Malus domesticuscompared to this one [31]. Interestingly, plant samples $\mathrm{F}, \mathrm{I}$, J, and $\mathrm{K}$ have lower $\mathrm{IC}_{50}$ value as compared to ascorbic acid $(45.88 \mathrm{mcg} / \mathrm{mL})$ demonstrating the highest scavenging activity compared to ascorbic acid. Kumawat et al., 2012, and Jadid et al., 2017, also demonstrated greater antioxidant properties of plant extract than ascorbic acid $[30,32]$.

Meanwhile, methanol is considered a major polar solvent as it can extract flavanols alkaloids, polyphenols, and saponins from plant materials in a high amount [30]. Some reports have also shown that the extracts of medicinal plants through methanol possess good pharmaceutical activity. The reducing ability of the methanol extract designates the presence of some compounds in the plant extracts which can contribute an electron and could react with free radicals to convert them into more stable products to terminate radical chain reactions. The only restriction found in DPPH activity is its solubility in organic solutions that cause a hurdle for the calculation of hydrophilic antioxidants [33]. Besides, the chemical structure of antioxidants also greatly influences the reaction of DPPH with antioxidants. Apart from this, Mentha piperita, E. wallchi, Brassica juncea, and Moringa olifera leaf act as potential antioxidant showing their half inhibitory maximum concentration value close to ascorbic acid as summarized in given Table 2.

Except for antioxidant activities the apple peel, Dattiwan, Moringa olifera, and other collected flora have healing abilities for various ailments and even some chronic diseases [31,34]. Several investigations are progressively carried out to isolate bioactive compounds from various medicinal plant parts included here because of their wide range of applications in pharmaceutical as well as in therapeutic activities. Therefore, phytomedicinal herbal plants are reliable in utilizing it as an alternative way in the medicinal field due to its affordable cost.

\section{Relationship between antioxidants with total phenolics and total} flavonoids

To correlate if the total phenolic content contributes to the antioxidant activity or not correlation analysis was carried out between TPC and TFC with antioxidant activity separately. In this research analysis, though extracts show high phenolic content with a high radical scavenging activity, good correlations could not be found among them. The antioxidant activity showed a weak correlation with phenols (Fig. 6 and 7).A linear regression analysis having the equation of $\mathrm{y}=3.4932 \mathrm{x}$ and $\mathrm{R}^{2}=0.3804$ failed to demonstrate a direct correlation between radical scavenging activity and phenolic content of extracts. This low correlation between total phenols and DPPH scavenging activity suggests that the major antioxidant components might not be phenolics, but could be sterols, ascorbic acid, carotenoids, or pigments which are also responsible to contribute towards antioxidant property [20]. There was no correlation between total flavonoids and radical scavenging activity (Fig. 6). This lack of correlation between scavenging activity and phenols and flavonoids is also demonstrated in kinds of literature by Ghasemi et al., 2009, Kaur 2014, and Ghimire et al., $2011[20,35,36]$. It is well-known that the flavonoids and other phenolic compounds have a certain structure, particularly hydroxyl position and number in the structure of a molecule that vastly affect the proton donating and radical scavenging activity [20]. Furthermore, the extracts are not only composed of phenol and flavonoids but are a mixture of different complex compounds possessing distinct activities. Besides, the Folin-Ciocalteu method used for the calculation of phenolic content is not considered an absolute measurement for the determination of the number of phenolic compounds [36]. The relationship of phenol, flavonoid, and $\mathrm{IC}_{50}$ values is also shown in the bar diagram (Fig. 8).

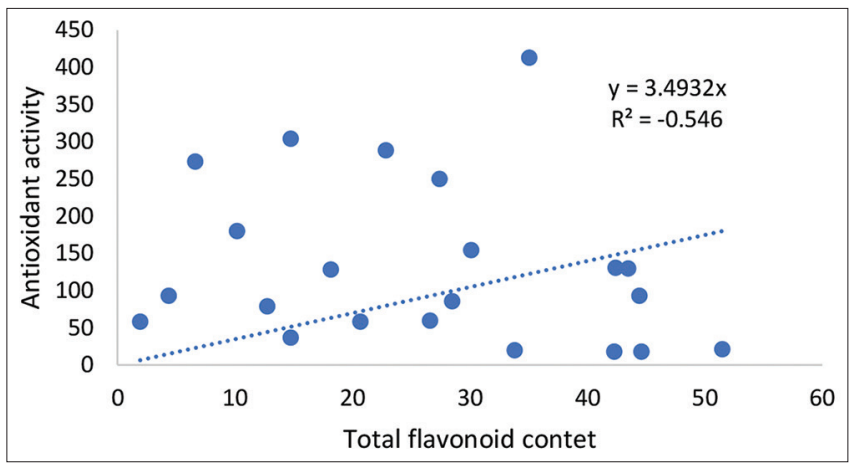

Fig. 6: Linear correlation between the antioxidant activity and total flavonoid content of the methanol extracts of 22 medicinal plants from different altitudes of Nepal

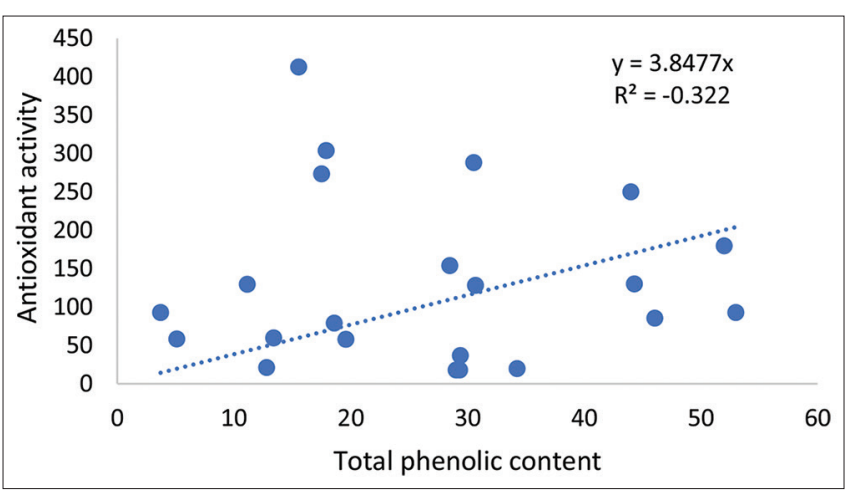

Fig. 7: Linear correlation between the antioxidant activity and total phenolic content of the methanol extracts of 22 medicinal plants collected from different altitudes of Nepal

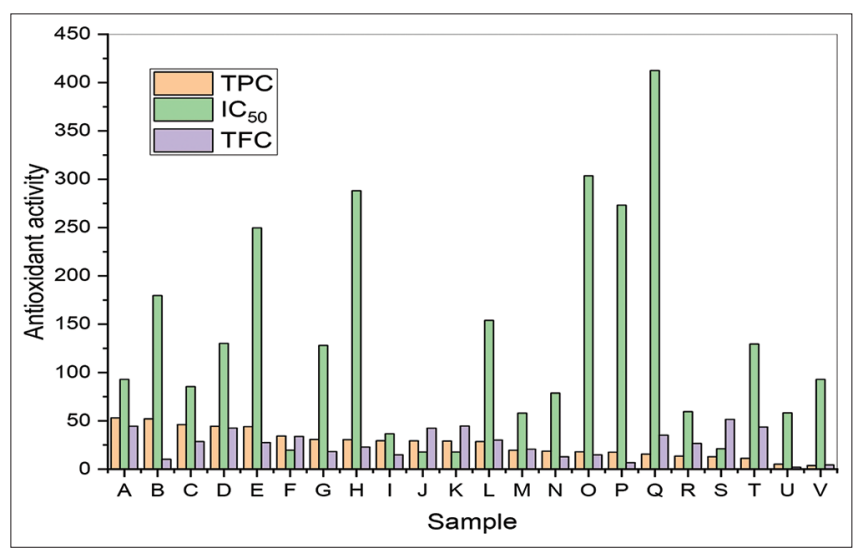

Fig. 8: Bar diagram representing the relationship of flavonoid, phenol, and IC50 value for antioxidant activity of the plant specimen

In contrast to this study, Kratchanova et al., 2010, have reported a high correlation between phenolic content and antioxidant activity [37]. In this study, only a few species such as A. vulgaris, T. chebula and M. domesticus showed a good correlation of antioxidant activity to phenolic content with an estimated coefficient of determination of $\mathrm{R}^{2}=0.96$, thus indicating that the high DPPH activity may be related to the phenolic compounds in these plants.

S. cumuni, M. piperita, Mimosa pudica, and E. wallichi though exhibited strong antioxidant activity they did not contain concomitantly high phenolic compounds. High antioxidant activity with low phenolics or flavonoids can be attributed to individual phenolic or non-phenolic compounds with specific high antioxidant activity. 
Similarly, C. aurantium, which has low phenolics and flavonoids revealed higher antioxidant activity. This might indicate the presence of active compounds of different polarities in this plant. Apart from phenol and flavonoids, various bioactive compounds such as Vitamin C, coumarins, terpenes, and quinoline have been reported in extracts of $C$. aurantium as reported by Suryawanshi, JAS 2011 that might be responsible for its high antioxidant property [38].

\section{CONCLUSION}

The toxicological effect of synthetic antioxidants in food pharmaceuticals and cosmetics has renewed the interest in uncovering natural antiradical from several plant species with traditional medicinal significance portraying pharmacological and phytochemical effects.

In conclusion, the present investigation on different medicinal plants found in the Terai region manifested a very good content of phenol and flavonoid along with certain degrees of antioxidant activity. In particular, the Malus domestica,Moringa oleifera,Rhododendron anthopogon, Persia americana,Syzygium cumini, and Mentha piperitaproclaimed themselves as a promising source of natural antioxidants and as a possible prophylactic agent in the pathogenesis of some common metabolic disorders that would be effectively enhanced in absence of these oxidoreductive agents. However, the total phenolic and flavonoid content revealed a weak correlation with the antioxidant activity of the investigated plant. Hence, the comprehensive effect of individual bioactive compounds involved in the antioxidant activity of specific plants required for their use as pharmacological and phytochemical agents in food, cosmetics, and pharmaceutical industries should be studied. Furthermore, it would be fascinating to know the chemical composition along with the mechanism of action of the antioxidants present in the plant extract for novel drug formulation.

\section{ACKNOWLEDGMENTS}

The authors would like to thank University Grants Commission (UGC) Nepal for the PhD fellowship to Bigyan Joshi.

\section{AUTHORS CONTRIBUTIONS}

All the authors contributed equally to this investigation and manuscript preparation.

\section{CONFLICT OF INTERESTS}

The authors declare no conflict of interest in the publication

\section{REFERENCES}

1. Do QD, Angkawijaya AE, Tran-Nguyen PL, Huynh LH, Soetaredjo FE, Ismadji S, et al. Effect of extraction solvent on total phenol content, total flavonoid content, and antioxidant activity of Limnophila aromatica. J Food Drug Anal 2014;22:296-302.

2. Chaudharia GM, Mahajan RT. Comparative antioxidant activity of twenty traditional Indian medicinal plants and its correlation with total flavonoid and phenolic content. Int J Pharm Sci Rev Res 2015;30:105-11.

3. Stankovic MS. Total phenolic content, flavonoid concentration and antioxidant activity of Marrubium peregrinum L. extracts. Kragujevac J Sci 2011;33:63-72.

4. Losada-Barreiro S, Bravo-Diaz C. Free radicals and polyphenols: The redox chemistry of neurodegenerative diseases. Eur J Med Chem 2017;133:379-402.

5. Chintalapani S, MS S, Narasu ML. Phytochemical screening and in-vitro antioxidant activity of whole plant extracts of Sesuvium portulacaastrum L. Asian J Pharm Clin Res 2018;11:322-7.

6. Pourmorad F, Hosseinimehr HJ, Shahabimadj N. Antioxidant activity, phenol and flavonoid contents of some selected Iranian medicinal plants. Afr J Biotechnol 2006;11:1142-5

7. Kurutas EB. The importance of antioxidants which play the role in cellular response against oxidative/nitrosative stress: Current state. Nutr J 2016;15:1-22.

8. Aryal S, Baniya MK, Danekhu K, Kunwar P, Gurung R, Koirala N. Total phenolic content, flavonoid content and antioxidant potential of wild vegetables from western Nepal. Plants 2019;8:1-12.
9. Rahman K. Studies on free radicals, antioxidants, and co-factors. Clin Interv Aging 2007;2:219-36.

10. Yashin A, Yashin Y, Xia X, Nemzer B. Antioxidant activity of spices and their impact on human health: A review. Antioxidants 2017;6:1-18.

11. Atanassova M, Georgieva S, Ivancheva K. Total, phenolic and total flavonoid contents, antioxidant capacity and biological contaminants in medicinal herbs. J Uni Chem Technol Metallurgy 2011;46:81-8.

12. Halilu ME, Balogun M, Lall N, Abubakar MS, Studies of in vitro antioxidant and cytotoxic activities of extracts and isolated compounds from Parinari curatellifolia (Chrysobalanaceae). J Nat Sci Res 2013;3:149-54.

13. Sharma V, Sharma S, Pracheta, Paliwal R. Withania somnifera: A rejuvenating ayurveda medicinal herb for the treatment of various human ailments. Int J PharmTech Res 2011;3:187-92.

14. Maharjan BL, Baral B. Antioxidant capacity and phenolic content of some Nepalese medicinal plants. Am J Plant Sci 2013;8:1660-5.

15. Chakree K, Settharaksa S, Siripongvutikorn S. Evaluation of total phenolic and flavonoid contents, antioxidant and anti-inflammatory activities of aqueous extract from Keang-hleung paste extract and its ingredients. Int Food Res J 2018;25:2435-43.

16. Mundhe KS, Kale AA, Gaikwad SA, Deshpande NR, Kashalkar RV. Evaluation of phenol, flavonoid contents and antioxidant activity of Polyalthia longifolia. J Chem Pharm Res 2011;3:764-9.

17. Williams WB, Cuvelier ME, Berset C. Use of a free-radical method to evaluate antioxidant activity. Food Sci Technol Lebens Wissens Technol 1995;28:25-30.

18. Pandey BP, Thapa R, Upreti A. Chemical composition, antioxidant and antibacterial activities of essential oil and methanol extract of Artemisia vulgaris and Gaultheria fragrantissima collected from Nepal. Asian Pac J Trop Med 2017;10:952-9.

19. Ben Nasr S, Aazza S, Mnif W, Miguel M. In-vitro antioxidant and anti-inflammatory activities of Pituranthos chloranthus and Artemisia vulgaris from Tunisia. Int J Appl Pharm Sci Res 2020;11:605-14.

20. Ghimire BK, Seong ES, Kim EH, Ghimeray AK, Yu CY, Ghimire BK, et al. A comparative evaluation of the antioxidant activity of some medicinal plants popularly used in Nepal. J Med Plants Res 2011;5: 1884-91.

21. Baral B, Vaidya GS, Maharjan BL, Da Silva JAT. Phytochemical and antimicrobial characterization of Rhododendron anthopogon from high Nepalese Himalaya. Botanica 2015;20:142-52.

22. Ruan ZP, Zhang LL, Lin YM. Evaluation of the antioxidant activity of Syzygium cumini leaves. Molecules 2008;13:2545-56.

23. Khurshid R, Ullah MA, Tungmunnithum D, Drouet S, Shah M, Zaeem A, et al. Lights triggered differential accumulation of antioxidant and antidiabetic secondary metabolites in callus culture of Eclipta alba L. PLoS One 2020;15:1-17.

24. Sinha S, Raghuwanshi R, Phytochemical screening and antioxidant potential of Eclipta prostrata (L) L-A valuable herb. Int J Pharm 2016;8:255-60.

25. Mwamatope B, Tembo D, Chikowe I, Kampira E, Nyirenda C. Total phenolic contents and antioxidant activity of Senna singueana, Melia azedarach, Moringa oleifera and Lannea discolor herbal plants. Sci Afr 2020;9:1-7.

26. Vaya J, Belinky PA, Aviram M. Antioxidant constituents from licorice roots: Isolation, structure elucidation and antioxidative capacity toward LDL oxidation. Free Radic Biol Med 1997;23:302-13.

27. Eshwarappa RS, Iyer RS, Subbaramaiah SR, Richard SA, Dhananjaya BL. Antioxidant activity of Syzygium cumini leaf gall extracts. Bioimpacts 2014;4:101-7.

28. Aryal S, Shrestha S, Devkota A, Bhandari N, Jha R. FTIR, GC-MS analysis and bioactivity studies of Withania somnifera L. of Nepalese origin. J Nepal Chem Soc 2020;41:36-45.

29. Mehta V, Sharma A, Kailkhura P, Malairaman U. Antioxidant, antiinflammatory and antidiabetic activity of hydroalcoholic extract of Ocimum sanctum: An in vitro and in-silico study. Asian J Pharm Clin Res 2016:9:44-9.

30. Jadid N, Hidayati D, Hartanti SR, Arraniry BA, Rachman RY, Wikanta W. Antioxidant activities of different solvent extracts of Piper retrofractum Vahl. Using DPPH assay. AIP Conf Proc 2017;1854:1-6.

31. Navarro M, Moreira I, Arnaez E, Quesada S, Azofeifa G, Vargas F, et al. Polyphenolic characterization and antioxidant activity of Malus domestica and Prunus domestica cultivars from Costa Rica. Foods 2018;7:1-19.

32. Kumawat BK, Gupta $M$, Tarachand and Singh Y. Free radical scavenging effect of various extracts of leaves of Balanites aegyptiaca (L.) Delile by DPPH method. Asian J Plant Sci Res 2012;2:323-9.

33. Ulewicz-Magulska B, Wesolowski M. Total phenolic contents and 
antioxidant potential of herbs used for medical and culinary purposes. Plant Foods Hum Nutr 2019;74:61-7.

34. Abdull Razis AF, Ibrahim MD, Kntayya SB. Health benefits of Moringa oleifera. Asian Pac J Cancer Prev 2014;15:8571-6.

35. Ghasemi K, Ghasemi Y, Ebrahimzadeh MA. Antioxidant activity, phenol and flavonoid contents of 13 citrus species peels and tissues. Pak J Pharm Sci 2009;22:277-81.

36. Kaur S, Mondal P. Study of total phenolic and flavonoid content, antioxidant activity and antimicrobial properties of medicinal plants. J Microbiol Exp 2014;1:1-6.

37. Kratchanova M, Denev P, Ciz M, Lojek A, Mihailov A. Evaluation of antioxidant activity of medicinal plants containing polyphenol compounds. Comparison of two extraction systems. Acta Biochem Pol 2010;57:229-34

38. Suryawanshi JA. An overview of Citrus aurantium used in the treatment of various diseases. Afr J Plant Sci 2011;5:390-5. 